\title{
Staining of human splenic sinusoids and demonstration of unusual banded structures by monoclonal antisera
}

\author{
AE STUART, A WARFORD \\ From the University Department of Pathology, Royal Victoria Infurmary, Newcastle upon Tyne NE1 4LP
}

SUMMARY The monoclonal antiserum OKT8 is useful as a marker of splenic sinusoids. Banded and fibrillary structures are also delineated by this antiserum; these appear to be different from the ring fibres of the spleen and the tentative suggestion is made that these represent basal plates or endothelial striations. The reactivity of sinus lining cells with a number of antisera is noted and the conclusion is drawn that splenic sinal endothelium differs substantially from the endothelium of blood vessels.

During an investigation into the immunohistology of the human spleen we noted that the splenic sinusoids were clearly marked by 12 and OKT 8 antisera. We wondered if this was due to an affinity of the antisera for endothelial cells, macrophages, ring fibres or basal plates. This paper describes our technical methods and illustrates the staining patterns found.

\section{Material and methods}

TISSUE PREPARATION

Tissue from seven fresh splenectomy specimens (four normal histology, two Hodgkin's disease, and one chronic lymphatic leukaemia) was used. For monoclonal antibody studies pieces of tissue $10 \mathrm{~mm}$ $\times 10 \mathrm{~mm} \times 3 \mathrm{~mm}$ were surrounded with cryoprotectant, snap frozen in isopentane precooled in liquid nitrogen and stored at $-70^{\circ} \mathrm{C}$. Blocks for paraffin wax embedding were fixed for $24 \mathrm{~h}$ in neutral buffered formaldehyde $\mathrm{pH} \mathrm{7.0}$ then overnight in formol sublimate before routine processing.

\section{LILLIE'S ALLOCHROME METHOD}

After removal of mercury and formalin pigments, paraffin sections were treated with the periodic acid-Schiff (PAS) reaction and counterstained with Sirius supra blue GL in aqueous picric acid. ${ }^{1}$ Basement membranes and ring fibres around the splenic sinuses are coloured purplish red and collagen fibres are stained blue.

Accepted for publication 12 May 1983
FIXATION

An acetone-chloroform-water fixative was prepared by adding four drops of distilled water to $2 \mathrm{ml}$ of mixture of equal volumes of the solvents. Thas $\omega$ fixative preserves the morphology of tissue better than acetone alone. It is not suitable for $\mathrm{B} 1$ and $\mathrm{B}$ preparations which were fixed in acetone only.

\section{MONOCLONAL METHOD}

The source specificities and dilution of antisera used $\underset{\vec{F}}{\vec{F}}$ is recorded in Table 1 . Freshly cut $5 \mu \mathrm{m}$ cryostat $\stackrel{3}{3}$ sections were treated as follows:

1 Air dry sections for $30 \mathrm{~min}$.

2 Fix in acetone for $20 \mathrm{~min}$ (I2 and B1 pre-parations) or acetone-chloroform-water to evapora-? tion (OKT3, 4, 6, 8, OKM1 and CLAT 200 preparations).

3 Wash twice in Tris-buffered saline $\mathrm{pH} 7.6 \frac{8}{3}$ (TBS).

4 Flood sections with $20 \%$ normal rabbit serum in 울 TBS for $10 \mathrm{~min}$.

5 Without rinsing apply mouse monoclonal antisera for $30 \mathrm{~min}$.

6 Wash twice in TBS.

7 Flood sections with $20 \%$ normal rabbit serum in TBS for $10 \mathrm{~min}$.

8 Without rinsing apply rabbit antimouse peroxi-? dase conjugated antisera for $30 \mathrm{~min}$.

9 Wash twice in TBS.

10 Demonstrate peroxidase activity using $\stackrel{\mathscr{D}}{+}$ diaminobenzidene.

11 Wash in running tap water.

12 Counterstain in toluidine blue or progressively 
Table 1 Source, specificities and dilutions of antisera

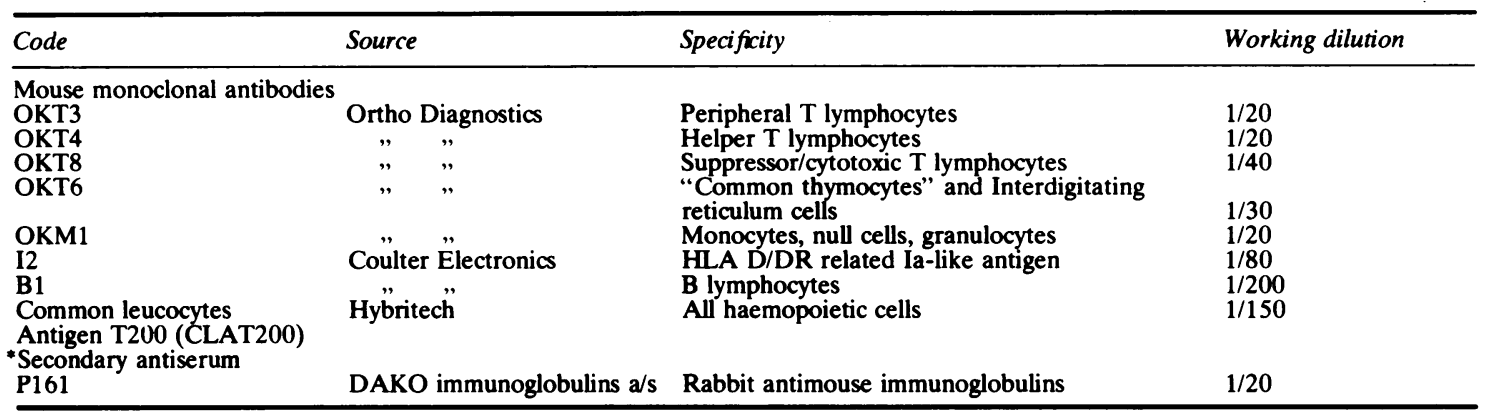

*This antiserum was absorbed with human IgG (Koch light 285501) in the ratio $2 \mathrm{mg} / 100 \mu \mathrm{l}$ neat antisera immediately before use.

in Mayer's haematoxylin.

13 Dehydrate clear and mount.

\section{REDUCTION OF BACKGROUND STAINING}

Sections were incubated in normal rabbit serum (Gibco Biocult 200-6120) before the antisera were applied.

\section{DIAMINOBENZIDENE VISUALISATION OF PEROXIDASE ACTIVITY}

A modified Graham and Karnovsky ${ }^{2}$ solution was used. Like Borowitz et al $^{3}$ we have shown that incorporation of imidazole in the diaminobenzidene-Tris buffer significantly improves antigen localisation. The working solution was prepared by adding $4 \mathrm{mg}$ diaminobenzidene tetrahydrochloride (Sigma) to 5 $\mathrm{ml}$ of TBS containing $0.01 \mathrm{M}$ imidazole. When this had fully dissolved $0.1 \mathrm{ml}$ of a $1 \%$ hydrogen peroxide solution was added. This solution was filtered before use.

\section{ALKALINE PHOSPHATASE}

The activity of this enzyme was demonstrated in 5 $\mu \mathrm{m}$ cryostat sections using the "Neufuchsin" method of Stutte. ${ }^{4}$ Sections were fixed in $10 \%$ formol-methanol at $4^{\circ} \mathrm{C}$ for $30 \mathrm{~s}$ before incubation in the substrate solution, naphthol-ASTRphosphate.

\section{Results}

Under the low power of the microscope the brown deposit of the immunoperoxidase reaction obtained with OKT8 delineated clearly the sinusoids. Little or

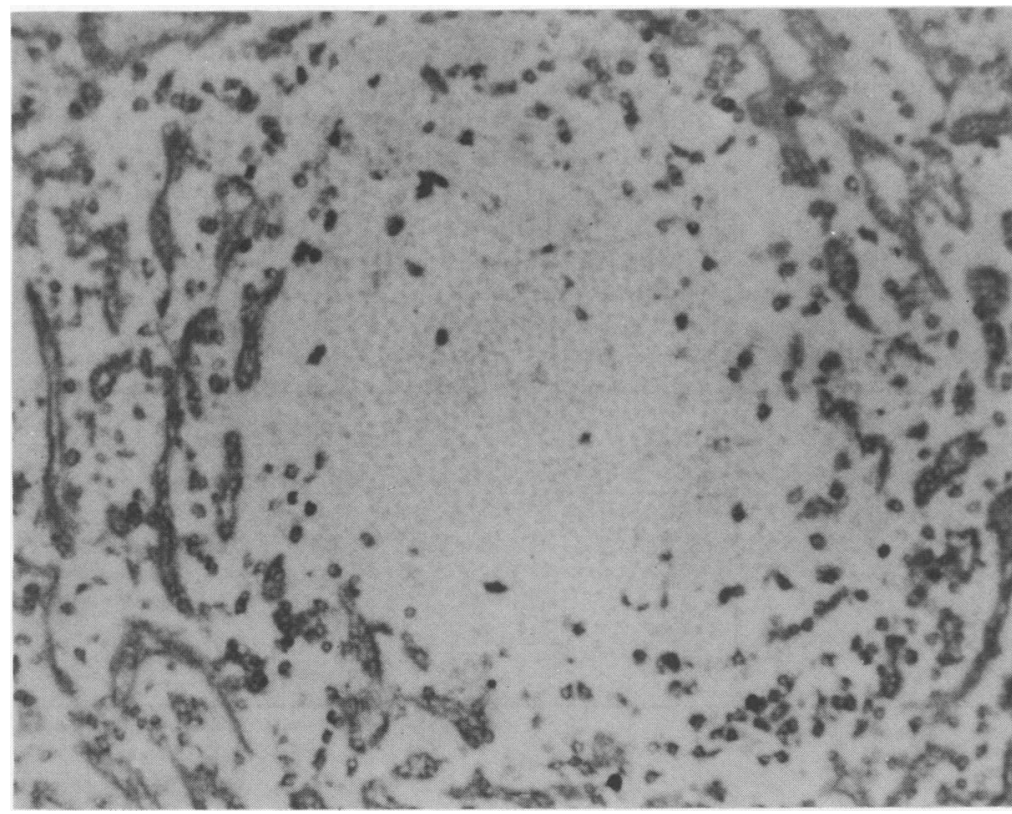

Fig. 1 Sinusoidal wall staining by OKT8. Immunoperoxidase $\times 300$ (approx). 


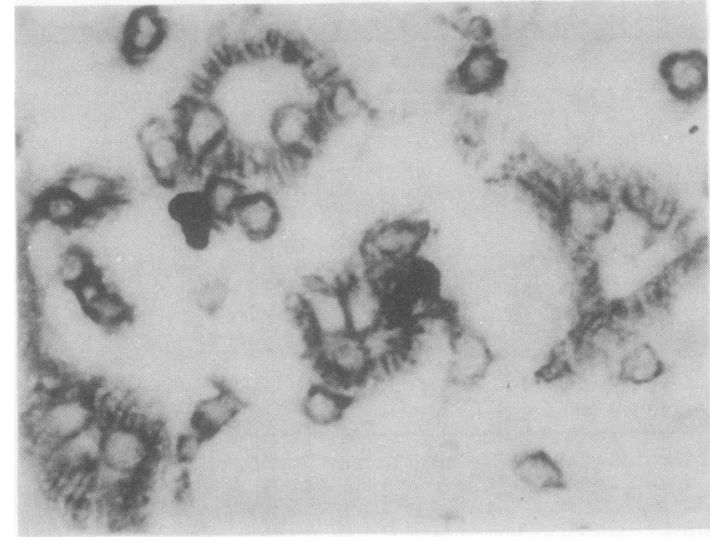

Fig. 2 Banded appearance in transverse section of sinusoids. OKT8 and immunoperoxidase $\times 600$ (approx).

no staining was visible in the Malpighian bodies or cords of Billroth. Occasional mononuclear cells situated within the sinusoids or cords were stained but this did not detract from the overall impression of specific sinusoidal wall staining (Fig. 1).

A more diffuse and much less discriminating picture was seen with anti-I2 where the majority of splenic cells gave a positive reaction. The pattern of sinusoidal staining was similar to that obtained with OKT8.

At a higher magnification the staining had a banded appearance. Cross sections of sinusoids showed darkly staining bands arranged at right angles to the lumenal surface and extending outwards to the periphery. The bands are separated by a gap of approximately $2-3 \mu \mathrm{m}$ width. It is difficult to say if these bands are located between endothelial cells or are truly intracytoplasmic structures (Fig. 2). Longitudinal sections through sinusoids showed fine linear streaks or fibres running parallel to the long axis (Fig. 3). The cytoplasm of the endothelial cells was also stained.

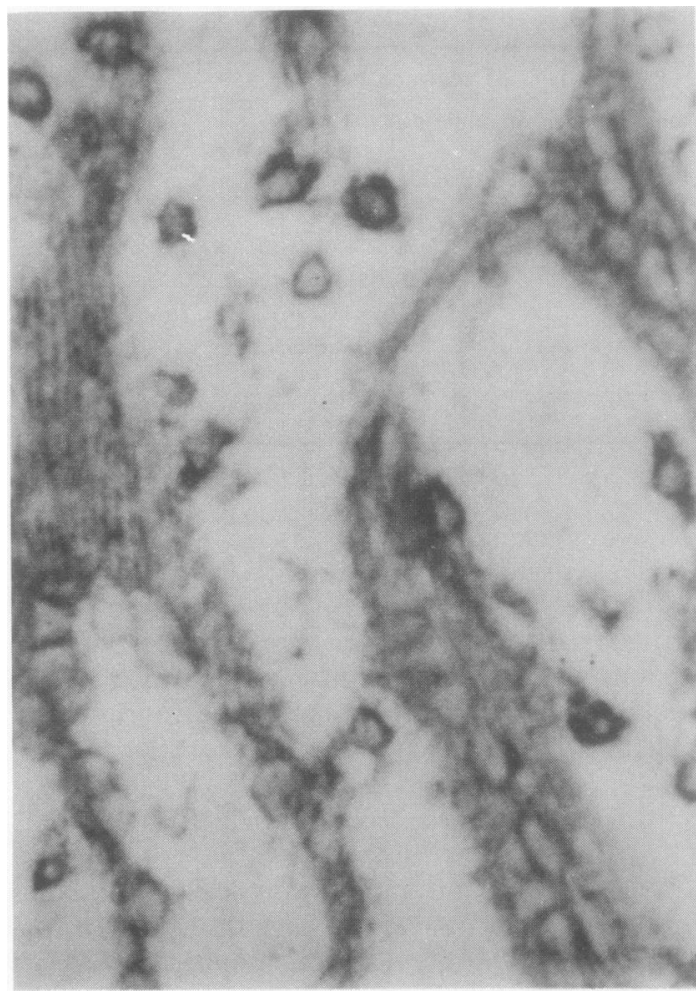

Fig. 3 Longitudinal fibrillar structures (top). OKT8 immunoperoxidase $\times 600$ (approx).

No delineation of sinuses or sinal cells was observed with the monoclonals OKT3, OKT6, OKM1, and B1. OKT4 gave equivocal results. Monoclonal CLAT200 stained most cells of the Malpighian body and sinal endothelial cells but did not produce the banded staining of grid structures seen with OKT8.

The reactivity of sinal endothelium with all markers is shown in Table 2.

Alkaline phosphatase activity was noted in the endothelium of trabecular vessels and collecting

Table 2 Reactivity of sinus lining cells with monoclonal antisera

\begin{tabular}{|c|c|c|c|c|c|c|c|}
\hline \multirow[b]{2}{*}{ Antibody } & \multicolumn{7}{|l|}{ Case } \\
\hline & 1 & 2 & 3 & 4 & 5 & 6 & 7 \\
\hline $\begin{array}{l}\text { OKT3 } \\
\text { OKT4 } \\
\text { OKT6 } \\
\text { OKT8 } \\
\text { I2 } \\
\text { CLAT200 } \\
\text { B1 } \\
\text { OKM1 }\end{array}$ & $\begin{array}{l}- \\
\pm \\
+ \\
+ \\
+ \\
\text { ND } \\
\text { ND } \\
-\end{array}$ & $\begin{array}{l}- \\
- \\
- \\
+ \\
+ \\
\text { ND } \\
\text { ND } \\
-\end{array}$ & $\begin{array}{l}- \\
\pm \\
+ \\
+ \\
+ \\
+ \\
- \\
-\end{array}$ & $\begin{array}{l}- \\
- \\
\overline{+} \\
+ \\
+ \\
- \\
-\end{array}$ & $\begin{array}{l}- \\
- \\
- \\
+ \\
\text { ND } \\
\text { ND } \\
- \\
-\end{array}$ & $\begin{array}{l}- \\
- \\
- \\
+ \\
+ \\
+ \\
- \\
-\end{array}$ & $\begin{array}{l}- \\
z \\
+ \\
+ \\
+ \\
+ \\
-\end{array}$ \\
\hline
\end{tabular}

$+=$ staining; $-=$ no staining; $\pm=$ equivocal staining; $\mathrm{ND}=$ not done.

Cases 1-4 Normal histology.

5-6 Hodgkin's disease.

7 Chronic lymphatic leukaemia. 


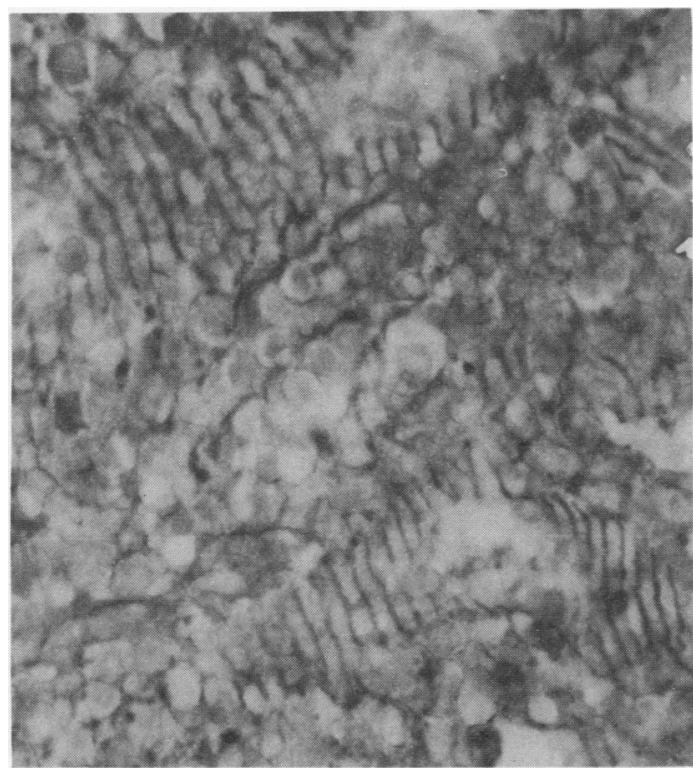

Fig. 4 Annular transverse hoops or ring fbres. Lillie's allochrome $\times 600$ (approx).

venules; sinus lining cells gave a negative reaction.

Classical ring fibres were demonstrated by Lillie's allochrome method in all cases (Fig. 4). These fibres coursed at right angles to the fibres outlined by OKT8 serum.

\section{Discussion}

The clear delineation of sinuses by the monoclonal antiserum OKT8 might be due to staining of endothelial cells or sinus associated cells such as the processes of macrophages as described by Burke and Simon ${ }^{5}$ or Schridde's delicate protoplasmic network composed of small spider-like cells which lie just without the endothelium and extend over its surface. The antimonocyte monoclonal OKM1 stains resident perifollicular macrophages as well as some histiocytes, and thus might reasonably be thought to react with sinus associated macrophages but no such staining pattern was observed. On the other hand the majority of sinus lining cells gave a distinct and positive reaction with OKT8 and it seems inescapable that these cells contain an antigen in common with suppressor or cytotoxic lymphocytes. Sinus lining cells gave positive reactions with anti-I2 and anticommon leucocyte antigen sera; the borderline reactions seen in two cases with OKT4 perhaps requires further investigation. The sinus lining cells failed to stain for alkaline phosphatase unlike the endothelium of the trabecular vessels and collecting venules. It is noteworthy that trabecular vascular endothelium failed to react with the OKT8 serum.

Endothelial cells isolated from umbilical veins do not react with OKT8 serum but give positive reactions with la-like antisera. ${ }^{6}$ The nature of splenic endothelium has been an unsettled question for many years and these marker studies provide additional evidence that vascular and splenic sinus endothelium differ substantially.

It first seemed to us that the banded and fibrillary structures corresponded to the annular or ring fibres which have been well described by King, Puchtler and Sweat.' These are stained by Lillie's allochrome method and although these fibres are often branched, the majority are annular, surrounding the sinusoids like the hoops of a barrel. However, the fibrils stained by OKT8 run longitudinally and are arranged at right angles to the ring fibres. Furthermore, cross sections of sinusoids reveal a banded

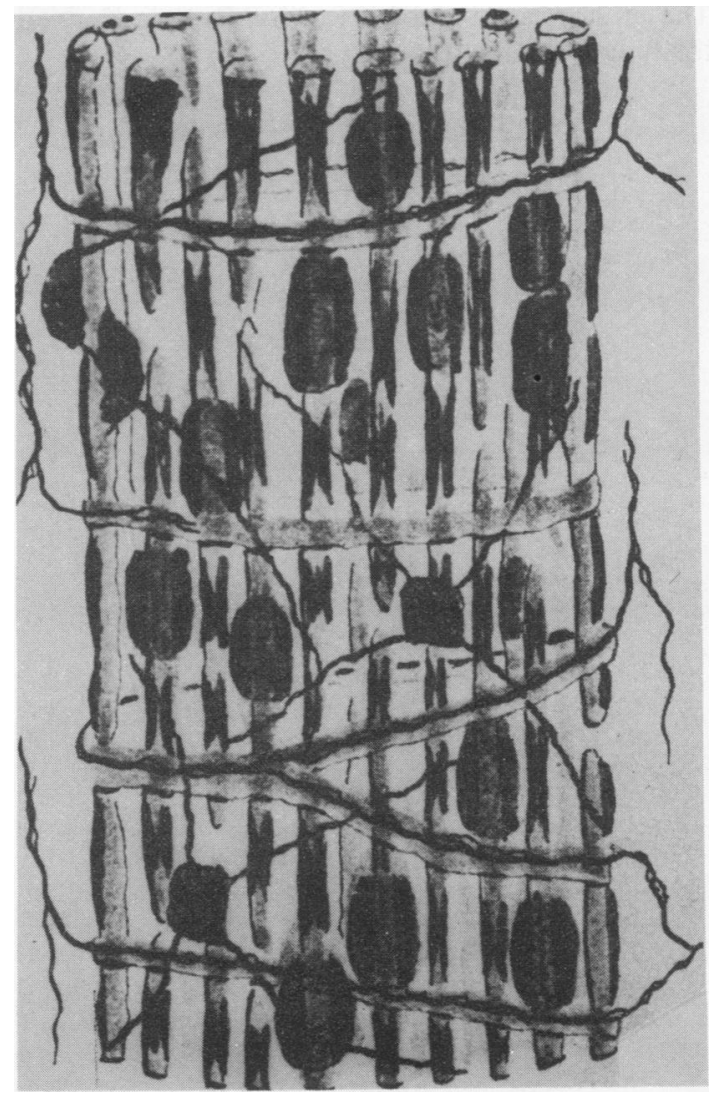

Fig. 5 Drawing of a sinusoid by Nathan Chandler Foot (1927) showing ring fibres and the endothelial cell striations. Reproduced with permission of the Editor, Dr Lachman, of Anatomical Record published by the Wistar Press. 
arrangement quite unlike the dot-like pattern seen in sections stained by Lillie's allochrome method. On the contrary, they resemble Foot's $s^{8}$ description of the basal plates or striations. He reviewed the early literature and showed that splenic endothelial cells were rod shaped rather than fusiform and contained areas staining blue with phosphotungstic acid haematoxylin (Fig. 5). He thought these were different from the argyrophilic reticular annuli. Our preliminary observations support the view that these basal plates or endothelial cell striations contain OKT8 antigen. It is not known if this reaction is adventitious or whether it conceals a purpose. Because these fibrillary structures form a grid through which cells must pass when migrating between cord and sinus, we put forward the view that the antigens associated with them act as biochemical signposts which modulate cellular traffic through the spleen.

The authors are indebted to Miss Brenda Kennedy for typing the manuscript.

\section{References}

' Sweat F, Puchtler H, Woo P. A light-fast modification of Lillie's allochrome stain. Arch Pathol 1964;78:73-5.

${ }^{2}$ Graham RC Jr, Karnovsky MJ. The early stages of absorption of $\equiv$ injected horseradish peroxidase in the proximal tubules of $क$ mouse kidney: ultrastructural cytochemistry by a new technique. J Histochem Cytochem 1966;14:291-302.

${ }^{3}$ Borowitz MJ, Croker BP, Burchette J. Immunocytochemical detection of lymphocyte surface antigens in fixed tissue sections. J Histochem Cytochem 1982;30:171-4.

4 Stutte HJ. Hexazotiertes Triamino-tritolyl-methanchlorid (Neufuchsin) als Kupplungssalz in der Fermenthistochemie. Histochemie 1967;8:327-31.

s Burke JS, Simon GT. Electron microscopy of the spleen. I. Anatomy and Microcirculation. Am.J Pathol 1970;58:127-55.

- Morris CS. The use of cell-specific antisera and lectins to analyse the nature of the Reed-Sternberg cell of Hodgkin's disease. University of Newcastle-upon-Tyne, PhD thesis, 1983.

' King JT. Puchtler H, Sweat F. Ring fibres in human spleens. Arch Pathol 1968;85:237-45.

8 Foot NC. Endothelium of the venous sinuses of the human spleen. Anat Rec 1927;36:91-102.

Requests for reprints to: Professor AE Stuart, Department $\bigcirc$ of Histopathology, The Royal Victoria Infirmary, Queen Victoria Road, Newcastle-upon-Tyne NE1 4LP, England. 